\title{
Aborted myocardial infarction in patients undergoing primary percutaneous coronary intervention
}

\author{
Małgorzata Pyda', Stefan Grajek', Weronika Oleśkowska-Florek², Maciej Lesiak', \\ Andrzej Siniawski ${ }^{1}$, Adrian Gwizdała $^{1}$, Marek Grygier $^{1}$, Aleksander Araszkiewicz $^{1}$ \\ $11^{\text {st }}$ Department of Cardiology of the Poznan University of Medical Sciences, Poland \\ 2 Department of Cardiology of Public Specialized Health Care Center, Inowrocław, Poland
}

\begin{abstract}
Introduction. The outcome of patients with ST-elevation myocardial infarction (STEMI) strongly depends on a successful reperfusion. In some patients receiving an effective treatment myocardial infarction can be aborted. Aim. The aim of the study was to estimate the incidence, clinical outcome, prognosis and inflammatory response in patients with aborted MI.

Material and methods. 119 consecutive patients with STEMI treated with a primary percutaneous coronary intervention $(\mathrm{pPCl})$ were enrolled in the study. Aborted $\mathrm{MI}$ was diagnosed when the maximal increase in cardiac enzymes (CK-MB) was up to twice the upper limit of normal (CK-MB $\leqslant 50 \mathrm{U} / \mathrm{I})$ and at least $50 \%$ reduction of ST-segment deviation was observed within 90 min of $\mathrm{pPCl}$.

Results. Aborted MI was diagnosed in 16 subjects (13.4\%). Patients with the aborted MI had lower serum troponin I levels $(p<0.0001)$. The time to treatment was significantly shorter in the aborted MI group (101 min vs. 220 min, $p<0.00001)$. Patients with aborted MI had a lower corrected TIMI frame count $(p<0.05)$ and a lower wall motion score index $(\mathrm{p}<0.005)$, less pronounced inflammatory response (lower serum levels of IL-6, $\mathrm{p}<0.01$, and MCP-1, $\mathrm{p}<0.05)$, higher ejection fraction six months after $\mathrm{MI}(72 \%$ vs. $64 \%, \mathrm{p}<0.05)$. None of the aborted $\mathrm{MI}$ patients died during the 3-year follow-up, while there were 13 deaths among patients with non-aborted MI.

Conclusions. The abortion of myocardial infarction results in a better outcome and more favorable prognosis. An inflammatory response is less pronounced in the aborted MI.
\end{abstract}

Keywords: STEMI, primary PCI, aborted MI.

\section{Introduction}

Myocardial infarction (MI) being the most dramatic manifestation of coronary artery disease leads to heart failure, other severe complications and is still associated with high mortality. The currently published ESC and ACC/AHA guidelines on ST-elevation myocardial infarction (STEMI) management show a great progress in the treatment of acute $\mathrm{MI}$ in the recent years [1, 2].

Immediate diagnosis and treatment in specialized centers may improve outcome. It is believed that some of the patients who have undergone successful reperfusion therapy will avoid myocardial necrosis [3]. This phenomenon, referred to as "aborted myocardial infarction", was first described in the Myocardial Infarction Triage and Intervention study (MITI) in subjects who received a very early treatment not followed by a raise of $\mathrm{Ml}$ biomarkers [4]. It showed that $40 \%$ of patients treated within 3 hours of symptoms had no evidence of infarction as measured by thallium scanning and $35 \%$ had minimal infarct size $<10 \%$ of the left ventricle. This population was further evaluated by Lamfers et al. in a study comprising 42 patients [5]. He 
defined aborted $\mathrm{MI}$ as both, a raise of cardiac enzymes (CPK or CK-MB) not higher than twice the upper limit of normal, and reduction of ST-segment deviation greater than or equal to $50 \%$. In the clinical practice myocardial necrosis is usually confirmed and quantified based on the serum cardiac biomarker levels. However, it is the troponin concentration which is considered the most sensitive marker of myocardial necrosis, and thus a definition of aborted $\mathrm{Ml}$ becomes more complex. Therefore Hassan et al. suggested troponin $T$ level of $1.5 \mu \mathrm{g} / \mathrm{L}$ as a cut-off value for aborted MI [6].

The assessment of resolution of initial ST-segment elevation in a standard 12-lead ECG is still considered to be a simple method of measuring myocardial perfusion and is therefore used for definition of aborted MI. Moreover, it allows for the determination of mortality risk in STEMI [7, 8].

\section{Material and methods}

The study protocol of the research was approved by our University Ethical Committee and all subjects gave informed consent to the work. Between January 2009 and December 2010 at the $1^{\text {st }}$ Department of Cardiology of the Poznań University of Medical Sciences we diagnosed 1800 cases of ACS, among which 750 were nSTEMI, 1050 - STEMI, 150 - referred to cardiac surgery, and 900 were treated with $\mathrm{pPCl}$. Only 119 patients with STEMI (82 men (69\%), mean age $59 \pm 10$ years) presented with the first onset of symptom lasting between 30 minutes and 6 hours. They were enrolled in the study and divided into two groups: non-aborted $\mathrm{MI}$ and aborted MI. Aborted MI was diagnosed when the maximal increase in cardiac enzymes (CK-MB or
(PK) was smaller than or equal to twice the upper limit of normal and resolution of ST-segment deviation was greater than or equal to $50 \%$ within 90 min of $\mathrm{pPCl}$ (index procedure).

Of the total cohort of 119 patients, 16 (13.4\%) met the criteria of aborted MI. Table 1 shows the basic clinical characteristics.

STEMI was diagnosed when ST segment elevation measured at J point was $\geqslant 0.1 \mathrm{mV}$ in at least two consecutive leads or $\geqslant 0.2 \mathrm{mV}$ in two adjacent precordial leads in a standard 12-lead ECG. The basic clinical and laboratory data (including total cholesterol, HDL and LDL cholesterol, triglycerides, leukocytes, creatinine, glucose, ESR, CPK, CK-MB and CTnl, interleukin 6 (IL-6), monocyte chemoattractant protein-1 (MCP-1) and CRP levels were analyzed.

Blood samples were collected before the index procedure as well as 4, 8, 12, 16, 24 and 36 hours of hospital arrival. A 12-lead ECG was recorded before and 90 minutes after the index procedure. In cases of anterior $\mathrm{Ml}$, the sum of ST-segment elevation in leads V1 to V6, I, and aVL was added to the sum of ST-segment depression in leads II, III, and aVF. For inferior MI, the sum of ST-segment elevation in leads II, III, and aVF (and I, aVL, V5, and V6, if present) was added to the sum of ST-segment depression in leads V1 to V4 $[3,4]$. The resolution of all ST-segment deviation was calculated based on the baseline ECG and the one recorded 90 minutes post $\mathrm{pPCl}$. The corrected TIMI Frame Count (CTFC) method was used for evaluation of flow in the infarct related artery [9].

An echocardiography was performed on the $2^{\text {nd }}$ or $3^{\text {rd }}$ day of hospitalization and 6 months after an ACS episode. The left ventricular (LV) end-diastolic volume

Table 1. Baseline characteristics of study population

\begin{tabular}{lcccc}
\hline & $\begin{array}{c}\text { Aborted MI } \\
n=16\end{array}$ & $\begin{array}{c}\text { Non-aborted MI } \\
n=103\end{array}$ & $p$ \\
\hline \multirow{2}{*}{ Sex } & Female & 9 & 28 & \multirow{2}{*}{0.0407} \\
\cline { 2 - 4 } & Male & 7 & 75 & 0.2237 \\
\hline Age (years) & $56 \pm 6$ & $60 \pm 11$ & 0.9886 \\
\hline BMI (kg/m2) & $26.1 \pm 5.3$ & $26.1 \pm 3.5$ & 0.0075 \\
\hline Arterial hypertension & $13(81 \%)$ & $43(42 \%)$ & 0.2194 \\
\hline Diabetes & $0(0 \%)$ & $15(15 \%)$ & 0.0678 \\
\hline Hypercholesterolemia & $16(100 \%)$ & $79(77 \%)$ & 0.2542 \\
\hline Tobacco smoking & $12(75 \%)$ & $58(56 \%)$ & 0.6396 \\
\hline Positive family history & $6(38 \%)$ & $29(28 \%)$ & 0.8684 \\
\hline Previous stroke & $0(0 \%)$ & $3(3 \%)$ & 0.3637 \\
\hline Peripheral arterial disease & $0(0 \%)$ & $11(11 \%)$ & 0.00001 \\
\hline Time to treatment $($ min) & $101.3 \pm 34.4$ & $220.7 \pm 65.1$ & 0.5368 \\
\hline Killip-Kimball class $>1$ & $0(0 \%)$ & $8(8 \%)$ &
\end{tabular}


(EDV), end-systolic volume (ESV), ejection fraction (EF) and left ventricular mass index (LVMI) were evaluated, wall motion score index (WMSI) was measured using the 4-grade wall motion score: 1 - normokinesis, 2 hypokinesis, 3 - akinesis, 4 - dyskinesis involving 17 segments of LV. The risk was stratified in all patients using the TIMI Risk Score by Morrow and Antman [10].

\section{Statistical analysis}

The normality of distribution of the analyzed variables was verified using the Kolmogorov-Smirnov test (K-S test). If a normal distribution was rejected, medians and extreme values were used. Normally distributed variables were presented as arithmetic mean \pm standard deviation. Results were found statistically significant if $p$ value scored $<0.05$. The T-student test was used to verify the statistical significance of differences between values showing a normal distribution; otherwise, the Mann-Whitney test was used. Qualitative characteristics were presented as a percentage (\%) of the observed cases. The Chi-square test was used to analyze the distribution differences between those variables.

The analyses of variance for repeatable measurements were carried out using the least significant difference (LSD) test for the variables that were observed on two separate occasions (EF, EDV, ESV). Discriminating and logistic regression analyses were also performed.

\section{Results}

The subjects with aborted MI were significantly more often female and hypertensive $(p<0.05)$. Age, BMI, diabetes mellitus, hypercholesterolemia, family history, tobacco smoking and Killip class were similar in both groups. The time to treatment was significantly shorter in patients with aborted Ml (101.3 \pm 34.4 vs. $220.7 \pm 65.1, p<0.00001$ ).

There were no significant differences between the two groups regarding the levels of total cholesterol, HDL and LDL cholesterol, triglycerides, leukocytes, glucose, creatinine, and erythrocyte sedimentation rate (ESR) (Table 2). The serum levels of IL-6 and MCP-1 before the reperfusion therapy were higher in the group of non-aborted MI. No significant difference was found between the two groups in serum CRP level before $\mathrm{pPCl}$.

No difference was found between the groups in the incidence of a single- or multi-vessel coronary heart disease. However, a single-vessel disease tended to be more frequent in subjects with aborted $\mathrm{Ml}(75 \%$ vs. $48 \%, p=0.07)$. The aborted MI patients had also a significantly better flow in the infarct related artery after the index procedure as measured with the corrected TIMI Frame Count (Table 3). Moreover, they had a significantly lower maximal ST-segment elevation 90 minutes after the procedure and a greater reduction of the maximal ST-segment elevation. In the non-aborted $\mathrm{MI}$ group, a pathological $\mathrm{Q}$ wave was observed significantly more often $(p<0.05)$. The study groups did not differ in terms of MI location, number of ST elevation leads, persistent ST segment elevation and heart rate (Table 4).

The echocardiographic parameters are summarized in Table 5. A follow-up examination at 6 months showed higher EF and lower EDV and ESV in the abort-

Table 2. Results of laboratory tests

\begin{tabular}{|c|c|c|c|}
\hline & $\begin{array}{c}\text { Aborted Ml } \\
\mathrm{n}=16\end{array}$ & $\begin{array}{c}\text { Non-aborted Ml } \\
n=103\end{array}$ & $\mathrm{p}$ \\
\hline Total cholesterol $(\mathrm{mmol} / \mathrm{l})^{*}$ & $7.1 \pm 1.3$ & $6.1 \pm 1.4$ & 0.0800 \\
\hline $\mathrm{LDL}(\mathrm{mmol} / \mathrm{l})^{*}$ & $4.5 \pm 1.3$ & $4.0 \pm 1.4$ & 0.2948 \\
\hline $\mathrm{HDL}(\mathrm{mmol} / \mathrm{l})^{*}$ & $1.7 \pm 0.7$ & $1.4 \pm 0.4$ & 0.1127 \\
\hline Triglicerydes $(\mathrm{mmol} / \mathrm{l})^{*}$ & $1.9 \pm 0.9$ & $1.7 \pm 0.9$ & 0.6080 \\
\hline Leukocytes (nG/l)* & $10.4 \pm 2.9$ & $11.2 \pm 4.1$ & 0.6243 \\
\hline Glucose $(\mathrm{mmol} / \mathrm{l})^{*}$ & $6.2 \pm 1.2$ & $7.2 \pm 3.9$ & 0.4347 \\
\hline $\operatorname{ESR}(\mathrm{mm} / \mathrm{h})^{*}$ & $11.8 \pm 6.8$ & $15.7 \pm 11.1$ & 0.3212 \\
\hline Creatinine $(\mu \mathrm{mol} / /)^{*}$ & $77.2 \pm 13.7$ & $87.7 \pm 22.1$ & 0.1917 \\
\hline Troponin I (ng/ml)* & $1.6 \pm 2.0$ & $18.2 \pm 18.0$ & 0.00006 \\
\hline CPK $(\mathrm{U} / \mathrm{I})^{*}$ & $202.1 \pm 234.0$ & $2346.0 \pm 1813.2$ & 0.00002 \\
\hline $\mathrm{CK}-\mathrm{MB}(\mathrm{U} / \mathrm{I})^{*}$ & $28.4 \pm 14.2$ & $206.4 \pm 154.3$ & 0.00002 \\
\hline IL-6 (pg/ml)* & $0.8 \pm 1.4$ & $19.9 \pm 54.4$ & 0.0071 \\
\hline MCP-1 (pg/ml)* & $130.0 \pm 123.2$ & $216.9 \pm 143.2$ & 0.0232 \\
\hline $\operatorname{CRP}(\mu \mathrm{g} / \mathrm{ml})^{*}$ & $4.4 \pm 4.3$ & $8.4 \pm 17.8$ & 0.7111 \\
\hline
\end{tabular}

*value \pm standard deviation 
Table 3. Angiographic data in study population

\begin{tabular}{lccc}
\hline & $\begin{array}{c}\text { Aborted MI } \\
n=16\end{array}$ & $\begin{array}{c}\text { Non-aborted MI } \\
n=103\end{array}$ & $P$ \\
\hline Single vessel disease & $12(75 \%)$ & $49(48 \%)$ & \multirow{2}{*}{0.0762} \\
\hline Multi vessel disease & $4(25 \%)$ & $54(52 \%)$ & \\
\hline CTFC (number of frames) $^{*}$ & $19.9 \pm 2.2$ & $36.1 \pm 30.0$ & 0.0080 \\
\hline *value \pm standard deviation & & &
\end{tabular}

Table 4. Electrocardiographic data of study population

\begin{tabular}{|c|c|c|c|}
\hline & $\begin{array}{c}\text { Aborted Ml } \\
n=16\end{array}$ & $\begin{array}{l}\text { Non-aborted MI } \\
n=103\end{array}$ & $p$ \\
\hline \multirow{3}{*}{$\begin{array}{l}\text { Location of Ml: } \\
\text { anterior } \\
\text { inferior } \\
\text { lateral }\end{array}$} & $9(56 \%)$ & $47(46 \%)$ & \multirow{3}{*}{0.3041} \\
\hline & $7(43 \%)$ & $49(47 \%)$ & \\
\hline & $0(0 \%)$ & $7(7 \%)$ & \\
\hline Number of leads with ST elevation* & $4.1 \pm 1.5$ & $4.0 \pm 1.8$ & 0.8732 \\
\hline \multirow{2}{*}{$\begin{array}{l}\text { Max. ST elevation }(\mathrm{mm})^{*} \text { : } \\
\text { at admission } \\
90 \text { minutes after PCI }\end{array}$} & $2.9 \pm 1.9$ & $3.2 \pm 1.6$ & 0.2371 \\
\hline & $0.4 \pm 0.5$ & $1.8 \pm 1.2$ & 0.000002 \\
\hline Reduction of max. ST elevation (\%)* & $83.8 \pm 22.4$ & $43.9 \pm 31.3$ & 0.00001 \\
\hline Persistent Q wave & $5(31 \%)$ & $72(70 \%)$ & 0.0064 \\
\hline Persistent ST elevation & $0(0 \%)$ & $22(21 \%)$ & 0.0549 \\
\hline Heart rate (/min)* & $70.0 \pm 10.5$ & $78.1 \pm 16.9$ & 0.0642 \\
\hline
\end{tabular}

Table 5. Echocardiographic parameters during hospitalization and 6 months after MI in study population

\begin{tabular}{|c|c|c|c|}
\hline & $\begin{array}{c}\text { Aborted Ml } \\
n=16\end{array}$ & $\begin{array}{c}\text { Non-aborted Ml } \\
n=103\end{array}$ & p \\
\hline EF-1 $(\%)^{*}$ & $62.1 \pm 7.7$ & $55.5 \pm 12.7$ & 0.0766 \\
\hline EF-2 after 6 months (\%)* & $72.0 \pm 4.5$ & $64.0 \pm 12.9$ & 0.0137 \\
\hline EDV-1 (ml)* & $69.5 \pm 32.4$ & $96.7 \pm 35.7$ & 0.0469 \\
\hline EDV-2 after 6 months (ml)* & $61.0 \pm 23.3$ & $90.4 \pm 37.1$ & 0.0259 \\
\hline ESV-1 (ml) ${ }^{*}$ & $25.5 \pm 13.2$ & $43.5 \pm 21.0$ & 0.0310 \\
\hline ESV-2 after 6 months $(\mathrm{ml})^{*}$ & $15.4 \pm 7.4$ & $35.9 \pm 24.7$ & 0.0119 \\
\hline WMSI * & $1.1 \pm 0.1$ & $1.3 \pm 0.3$ & 0.0048 \\
\hline LV mass index-1* & $190.9 \pm 46.1$ & $269.7 \pm 281.9$ & 0.0147 \\
\hline LV mass index-2 after 6 months* & $177.6 \pm 47.1$ & $257.1 \pm 282.2$ & 0.0161 \\
\hline
\end{tabular}

*value \pm standard deviation

ed MI patients. Both, WMSI and LVMI, were lower during the hospitalization (LVMI-1) as well as in the follow-up examination (LVMI-2). The TIMI Risk Score was similar in both groups ( 2 p vs. $2 p$ ).

Thirteen (12.6\%) out of 103 non-aborted MI patients and none of the aborted MI group died during the 3-year follow-up. Due to a relatively small and unbalanced number of patients in each group, the Kaplan-Meier survival curve in Figure 1 failed to show a significant difference between the studied groups.

\section{Discussion}

We diagnosed aborted MI when: (i) a patient suffered a typical chest pain for over $30 \mathrm{~min}$; and (ii) the maxi- mal increase in cardiac enzymes (CK-MB or CPK) was smaller than or equal to twice the upper limit of normal; and (iii) the resolution of the initial ST-segment deviation was greater than or equal to $50 \%$ [5]; and (iv) there was a significant coronary artery stenosis at the territory of suspected ischemia. In our study the aborted MI patients accounted for $13.4 \%$ which is a similar result $(15 \%)$ to the one reported by Sciagra et al. [11], Hassan et al. (18\%) [6] and Vasile (9.1\%) [12].

In 2012 the European Society of Cardiology proposed the third universal definition of myocardial infarction based, among others, on a very sensitive marker - troponin; however the definition of aborted MI was not included [13]. Following the MI definition, all of the studied patients had elevated troponin lev- 


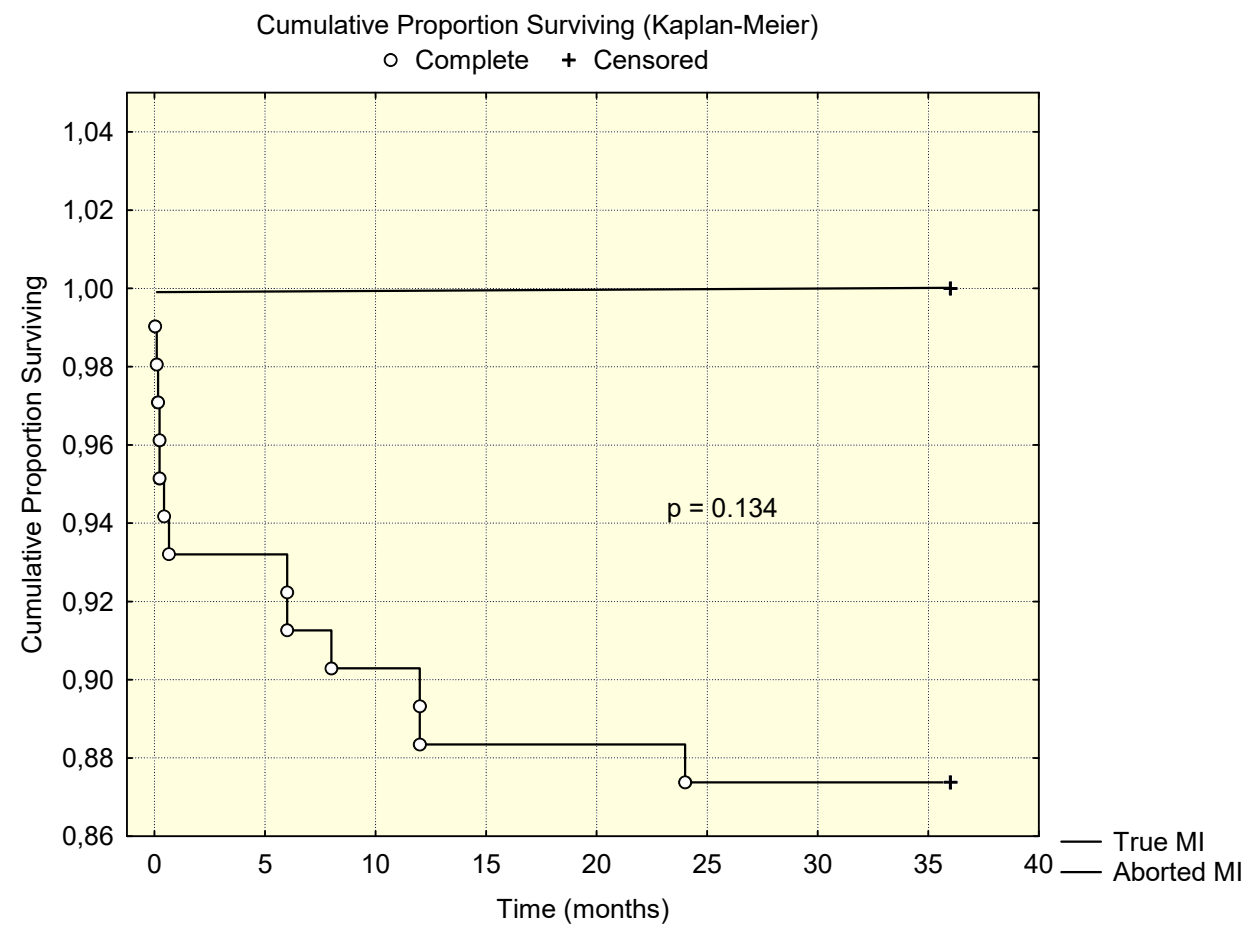

Figure 1. Kaplan-Meier Curves for both groups of study population

els. The frequency of aborted MI would be $0 \%$ when using $99^{\text {th }}$ percentile cut-off of troponin level. The time to treatment in the studied population was never shorter than 60 minutes. This is probably why all of our studied patients experienced myocardial necrosis reflected by elevated troponin levels. However, as mentioned earlier, troponin is a very sensitive marker allowing detection of even minor myocardial damage involving a small myocyte count. Consequently, a question arises if it would be at all feasible for clinical practice to implement a definition of aborted MI based on the detection of elevated troponin levels. This issue remains controversial. In a study by Vasile at al. the mean troponin T level in aborted MI was $0.82 \pm 1.82$ vs. $5.64 \pm$ $6.18 \mu \mathrm{g} / \mathrm{l}$ in the entire study population [12].

It seems that similar concern arose in Hassan's group when suggesting a troponin cut-off point for their definition of aborted MI. They included into the aborted MI group certain patients. The discriminating criteria were troponin $\mathrm{T}<1.5 \mu \mathrm{g} / \mathrm{L}$ and $\mathrm{CK}$ release up to 3 -fold the upper limit of normal [6]. Therefore, this approach allowed to identify patients with a more favorable outcome. It is commonly recognized that $\mathrm{pPCl}$ itself is associated with cardiac biomarker release. Similarly,in our study the mean troponin level in the aborted Ml group was also $1.6 \pm 2.0 \mu \mathrm{g} / \mathrm{L}$ [3] while being significantly higher in the non-aborted $\mathrm{MI}$ subjects $(18.2 \pm 18.0 \mu \mathrm{g} / \mathrm{L})$.
In present study, time to treatment was significantly shorter in the aborted Ml patients, which is consistent with other reports $[3,11]$. This further confirms that time is an important factor influencing the extension of necrosis and mortality in patients with STEMI treated with $\mathrm{pPCl}[14,15]$.

We also observed, as shown in other studies, that subjects with aborted myocardial infarction had better flow in the infarct related artery (corrected TIMI Frame Count) [16-18].

Antiplatelet therapy involving GP IIb/IIla inhibitors significantly improves myocardial perfusion and limits necrosis [19].

To date, our study first examined the inflammatory reaction following a primary $\mathrm{PCl}$ in patients with aborted MI. Less pronounced inflammatory response is an important finding, not reported previously in any studies concerning aborted MI. It translates to a smaller area of myocardial necrosis and myocardial scarring and remodeling of the left ventricle [20, 21]. Our study documented that patients with aborted $\mathrm{Ml}$ had lower plasma levels of both, IL-6 and MCP-1 (Table 2). Higher MCP-1 and IL- 6 plasma levels have been demonstrated to correlate with increased risk of death and outcome in patients with acute coronary syndrome [22-24].

We have also observed that patients with aborted $\mathrm{MI}$ had a better left ventricular function, which significantly improves the prognosis of infarct survivors [25-27]. 
In their paper, Eitel at al. showed that $56 \%$ of patients with aborted MI had no scar detected while $44 \%$ of subjects had only minor necrosis in MRI study [28]. It may implicate limited unfavorable remodeling and better prognosis.

The pathological $Q$ wave was more frequently observed in the non-aborted Ml patients (Table 4). Usually, the presence of pathological $Q$ wave is an electrocardiographic evidence that more than a half of the wall thickness is affected by a scar. As an electrocardiographic sign, the $\mathrm{Q}$ wave however not always truly reflects the size of necrosis [29]. On the other hand, the absence of $\mathrm{Q}$ wave is an excellent predictor of left ventricular function recovery following a successful reperfusion therapy [30].

The definition of aborted $\mathrm{Ml}$ used in our study seems justified, as patients with aborted MI had better prognosis which manifested itself in only slightly impaired left ventricular function.

Based on our results, we can conclude that the definition of aborted $\mathrm{MI}$ after $\mathrm{pPCl}$ should be revised to account for the troponin criteria proposed by Hassan [6]. Whether patients with aborted MI should be administered the same treatment for the secondary prevention as those with non-aborted $\mathrm{Ml}$ is still an open issue.

Our study was a retrospective analysis comprising a relatively small group of patients which may be its limitation. Nevertheless, our results documented that abortion of myocardial infarction by prompt reperfusion remains an essential target for $\mathrm{PCl}$.

\section{Conclusions}

The abortion of myocardial infarction by means of a fast and efficient reperfusion therapy results in a better clinical outcome and more favourable prognosis. The inflammatory response is less pronounced in subjects with aborted MI. Therefore, the abortion of MI should become a target in the acute treatment of myocardial infarction.

\section{Acknowledgements}

\section{Conflict of interest statement}

The authors declare that there is no conflict of interest in the authorship or publication of contribution.

\section{Funding sources}

There are no sources of funding to declare.

\section{References}

1. O'Gara PT, Kushner FG, Ascheim DD, Casey DE, Chung MK, De Lemos J, et al. ACCF/AHA Guideline for the Management of ST-Elevation Myocardial Infarction: Executive Summary: A Report of the American College of Cardiology Foundation/American Heart Association Task Force on Practice Guidelines. Circulation 2013;127:529-55.

2. Van de Werf F, Bax J, Betriu A, Blomstrom-Lundqvist $C$, Crea F, Falk V Filippatos G, et al. Management of acute myocardial infarction in patients presenting with persistent ST-segment elevation: the Task Force on the Management of ST-Segment Elevation Acute Myocardial Infarction of the European Society of Cardiology. Eur Heart J. 2008;29:2909-45.

3. Taher T, Fu Y, Wagner GS, Goodman SG, Fresco C, Granger $C B$, et al. Aborted myocardial infarction in patients with ST-segment elevationlnsights from the assessment of the safety and efficacy of a new thrombolytic regimen-3 trial electrocardiographic substudy. J Am Coll Cardiol. 2004;44:38-44.

4. Weaver W, Hallstrom AP, Litwin PE, Martin JS, Kudenchuk PJ, Eisenberg M. Prehospital-initiated vs hospital-initiated thrombolytic therapy: The myocardial infarction triage and intervention trial. J Am Med Assoc. 1993;270:1211-16.

5. Lamfers EJP, Hooghoudt TEH, Uppelschoten A, Stolwijk PWJ, Verheugt FWA. Effect of prehospital thrombolysis on aborting acute myocardial infarction. Am J Cardiol. 1999; 84: 928-30.

6. Hassan AK, Jukema JW, Van der Laarse A, Hasan-Ali H, Wolterbeek R, Van der Kley F, et al. Incidence, patient characteristics and predictors of aborted myocardial infarction in patients undergoing primary $\mathrm{PCl}$ : prospective study comparing pre- and in-hospital abciximab pretreatment. Eurolntervention. 2009;4:662-68.

7. Antman EM, Cooper HA, Gibson CM, De Lemos JA, McCabe $\mathrm{CH}$, Giugliano RP, et al. Determinants of improvement in epicardial flow and myocardial perfusion for ST elevation myocardial infarction. Insights from TIMI 14 and InTIME-II. Eur Heart J. 2002;23:928-33.

8. Schröder R, Dissmann R, Brüggemann T, Wegscheider K, Linderer $T$, Tebbe $U$, et al. Extent of early ST segment elevation resolution: A simple but strong predictor of outcome in patients with acute myocardial infarction. J Am Coll Cardiol. 1994;24:384-91.

9. Gibson CM, Cannon CP, Daley WL, Dodge JT, Alexander B, Marble SJ McCabe CH, et al. TIMI Frame Count . Circulation. 1996; 93:879-88.

10. Morrow DA, Antman EM, Charlesworth A, Cairns R, Murphy SA, De Lemos JA, et al. TIMI Risk Score for ST-Elevation Myocardial Infarction: A Convenient, Bedside, Clinical Score for Risk Assessment at Presentation. Circulation. 2000;102:2031-37.

11. Sciagra R, Parodi G, Sotgia B, Antoniucci D, Pupi A. Determinants of final infarct size and incidence of aborted infarction in patients treated with primary coronary intervention and adjunctive abciximab therapy. Nuklearmed. 2008;47:139-45.

12. Vasile VC, Babuin L, Ting HH, Bell MR, Orme NM, Yuan BY, et al. Aborted myocardial infarction: Is it real in the troponin era? Am Heart J. 2009;157:636-41. 
13. Thygesen K, Alpert JS, Jaffe AS, Simoons ML, Chaitman $B R$, White HD, et al. Third universal definition of myocardial infarction. Eur Heart J. 2012;33:2551-67.

14. De Luca G, Suryapranata H, Ottervanger JP, Antman EM. Time Delay to Treatment and Mortality in Primary Angioplasty for Acute Myocardial Infarction . Circulation. 2004;109:1223-25.

15. De Luca G, Ernst N, Zijstra F, van't Hof AWJ, Hoorntje JCA, Dambrink J-HE, et al. Preprocedural TIMI flow and mortality in patients with acute myocardial infarction treated by primary angioplasty. J Am Coll Cardiol. 2004;43:1363-67.

16. Araszkiewicz A, Lesiak M, Grajek S, Mularek-Kubzdela T, Cieśliński A. Wartość prognostyczna oceny przepływu metodą corrected TIMI Frame Count u chorych z przepływem TIMI 3 w tętnicy odpowiedzialnej za zawał po skutecznej pierwotnej interwencji wieńcowej Predictive value of corrected TIMI Frame Count in patients with TIMI 3. Folia Cardiol. 2004;12:895-902.

17. Hamada S, Nishiue T, Nakamura S, Sugiura T, Kamihata $\mathrm{H}$, Miyoshi $\mathrm{H}$, et al. TIMI frame count immediately after primary coronary angioplasty as a predictor of functional recovery in patients with TIMI 3 reperfused acute myocardial infarction. J Am Coll Cardiol. 2001;38:666-71.

18. Edep ME, Guarneri EM, Teirstein PS, Phillips PS, Brown DL. Differences in TIMl frame count following successful reperfusion with stenting or percutaneous transluminal coronary angioplasty for Acute Myocardial Infarction. Am J Cardiol. 1999;83:1326-29.

19. Eitel I, Desch S, Schindler K, Fuernau G, Schuler G, Thiele $\mathrm{H}$. Aborted myocardial infarction in intracoronary compared with standard intravenous abciximab administration in patients undergoing primary percutaneous coronary intervention for ST-elevation myocardial infarction. Int J Cardiol. 2011;153:21-25.

20. Ohtsuka T, Hamada M, Inoue K, Ohshima K, Suzuki J, Matsunaka T, et al. Relation of Circulating Interleukin- 6 to Left Ventricular Remodeling in Patients with Reperfused Anterior Myocardial Infarction. Clin Cardiol. 2004; 27:417-20.

21. Frangogiannis NG, Smith CW, Entman ML. The inflammatory response in myocardial infarction. Cardiovasc Res. 2002;53:31-47.

22. Lindahl B, Toss H, Siegbahn A, Venge P, Wallentin L. Markers of Myocardial Damage and Inflammation in Relation to Long-Term Mortality in Unstable Coronary Artery Disease. New Engl J Med. 2000;343,1139-47.

23. Kanda $T$, Inoue $M$, Kotajima N, Fujimaki S, Hoshino $Y$, Kurabayashi $M$, et al. Circulating Interleukin- 6 and Interleukin-6 Receptors in Patients with Acute and Recent Myocardial Infarction. Cardiology. 2000;93:191-96.
24. De Lemos JA, Morrow DA, Sabatine MS, Murphy SA, Gibson CM, Antman EM, et al. Association Between Plasma Levels of Monocyte Chemoattractant Protein-1 and Long-Term Clinical Outcomes in Patients With Acute Coronary Syndromes . Circulation. 2003;107:690-95.

25. Halkin A, Stone GW, Dixon SR, Grines CL, Tcheng JE, Cox $D A$, et al. Impact and Determinants of Left Ventricular Function in Patients Undergoing Primary Percutaneous Coronary Intervention in Acute Myocardial Infarction. Am J Cardiol. 2005;96:325-31.

26. St John Sutton M, Pfeffer MA, Plappert T, Rouleau JL, Moyé LA, Dagenais GR, et al. Quantitative two-dimensional echocardiographic measurements are major predictors of adverse cardiovascular events after acute myocardial infarction. The protective effects of captopril. . Circulation. 1994;89:68-75.

27. Otterstad JE, St. John Sutton M, Frøland G, Skjærpe T, Graving B, Holmes I. Are Changes in Left Ventricular Volume as Measured with the Biplane Simpson's Method Predominantly Related to Changes in its Area or Long Axis in the Prognostic Evaluation of Remodelling Following a Myocardial Infarction? Eur J Echocardiogr. 2001;2:118-25.

28. Eitel I, Desch S, Sareban M, Fuernau G, Gutberlet M, Schuler $\mathrm{G}$, et al. Prognostic significance and magnetic resonance imaging findings in aborted myocardial infarction after primary angioplasty. Am Heart J. 2009;158:806-13.

29. Wu E, Judd RM, Vargas JD, Klocke FJ, Bonow RO, Kim RJ. Visualisation of presence, location, and transmural extent of healed Q-wave and non Q-wave myocardial infarction. Lancet. 2001;357:21-28.

30. Surber R, Schwarz G, Figulla HR, Werner GS. Resting 12-lead electrocardiogram as a reliable predictor of functional recovery after recanalization of chronic total coronary occlusions. Clin Cardiol. 2005;28:293-97.

Acceptance for editing: 2015-02-19 Acceptance for publication: 2015-03-30

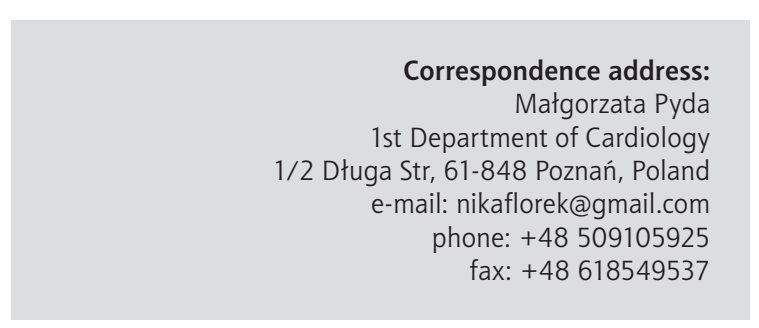

